Artículos Científicos

\title{
Evaluación del logro del perfil de egreso en grados universitarios: tendencias y desafíos
}

\begin{abstract}
Assessment of the Achievement of the Graduation Profile in University Degrees: Trends and Challenges
\end{abstract}

Avaliação da conquista do perfil de graduação em diplomas universitários: tendências e desafios

Ludencino Amador Huamán Huayta Universidad Nacional del Centro del Perú, Perú Ihuaman@uncp.edu.pe https://orcid.org/0000-0001-8042-9752

Teresa Nilda Pucuhuaranga Espinoza Universidad Nacional del Centro del Perú, Perú tpucuhuaranga@uncp.edu.pe https://orcid.org/0000-0003-0757-2995

Nora Esther Hilario Flores Universidad Nacional del Centro del Perú, Perú nhilario@uncp.edu.pe https://orcid.org/0000-0003-2196-9673 

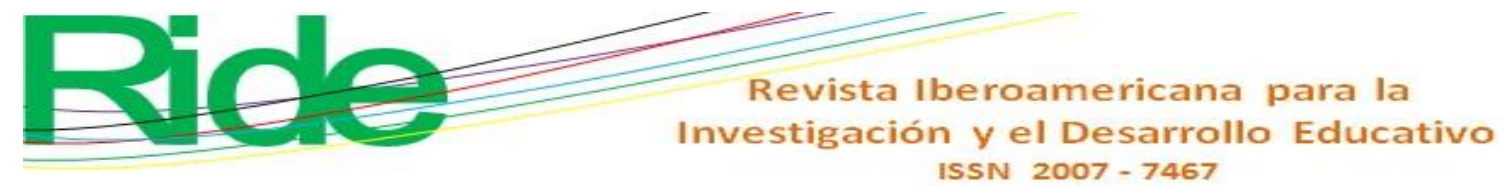

\section{Resumen}

La expectativa del estudiante universitario es formarse profesionalmente para insertarse en el campo laboral y mostrar un desempeño óptimo. Para ello, debe evidenciar el logro del perfil de egreso en el grado que oferta la universidad, según su modelo educativo. La cuestión es cómo se desarrollan y se evalúan las competencias declaradas en el perfil de egreso, cuáles son los mecanismos de aseguramiento del avance y logro que satisfagan las expectativas del estudiante, de los empleadores y de la sociedad. Por esta razón el objetivo fue analizar las principales tendencias y desafíos respecto a la evaluación del logro del perfil de egreso en los grados universitarios. Se realizó un estudio descriptivo e interpretativo con base en el metaanálisis documental de 21 publicaciones ubicadas en Google Académico, Scielo, Dialnet, Fuente Académica Plus y Ebsco. Los criterios de inclusión fueron: artículos científicos que presentaran experiencias de evaluación del logro del perfil de egreso, grados o titulaciones universitarias diversas, publicados entre 2009 y 2019. Se identificaron cinco tendencias de evaluación del logro del perfil de egreso: $a$ ) coherencia entre plan de estudios e instrumentos de evaluación de asignaturas con el perfil de egreso; $b$ ) al final de los estudios universitarios; $c$ ) progresiva durante la formación; $d$ ) progresiva y al final de los estudios, $\mathrm{y}$ e) evaluación por egresados y empleadores. Conjuntamente muestran significativos aportes en cuanto a estrategias, instrumentos, actores involucrados y resultados que abren perspectivas de investigación y desarrollo. Se concluye que existe la necesidad de implementar un sistema progresivo, integral y participativo de evaluación del logro del perfil de egreso en los grados universitarios, basado en el conocimiento, la experiencia previa y los desafíos planteados a la universidad.

Palabras claves: evaluación, grado universitario, logro del perfil de egreso. 


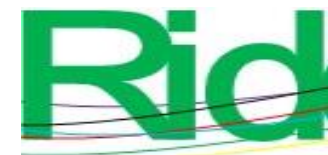

\section{Abstract}

The expectation of the university student is to train professionally to enter the labor field showing optimal performance. For this, it must demonstrate the achievement of the graduation profile in the degree awarded by the university, according to its educational model. The question is how are the competences declared in the graduation profile developed and evaluated, what are the mechanisms for ensuring progress and achievement that meet the expectations of the student, employers and society. For this reason, the objective was to analyze the main trends and challenges regarding the assessment of the achievement of the graduation profile in the university titles. A descriptive and interpretive study was carried out based on the documentary meta-analysis of 21 publications located in Google Academic, Scielo, Dialnet, Academic Source Plus and Ebsco. The inclusion criteria were: scientific articles that present experiences evaluating the achievement of the graduation profile, various degrees or university titles, with a publication period of 2009 to 2019. Five tendencies of assessment of the achievement of the graduation profile were identified: $a$ ) coherence between study plan and instruments of assessment of subjects with the graduation profile; $b$ ) at the end of university studies; $c$ ) progressive during training; $d$ ) progressive and the end of studies, and $e$ ) evaluation by graduates and employers. All of them show significant contributions in terms of strategies, instruments, actors involved and results that open research and development perspectives. It is concluded that there is a need to implement a progressive, comprehensive and participatory system for assessment of the achievement of the graduation profile in university degrees, based on knowledge, previous experience and the challenges posed to the university.

Keywords: assessment, university degree, achievement of the graduation profile. 


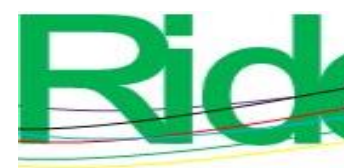

Revista Iberoamericana para la Investigación y el Desarrollo Educativo ISSN $2007-7467$

\section{Resumo}

A expectativa do estudante universitário é treinar profissionalmente para entrar no campo do trabalho e mostrar um ótimo desempenho. Para isso, deve demonstrar a conquista do perfil de graduação na graduação oferecida pela universidade, de acordo com seu modelo educacional. A questão é como as competências declaradas no perfil da graduação são desenvolvidas e avaliadas, quais são os mecanismos para garantir o progresso e a realização que atendem às expectativas do aluno, empregadores e sociedade. Por esse motivo, o objetivo foi analisar as principais tendências e desafios relacionados à avaliação do desempenho do perfil de graduação em graus universitários. Um estudo descritivo e interpretativo foi realizado com base na metanálise documental de 21 publicações localizadas no Google Scholar, Scielo, Dialnet, Academic Source Plus e Ebsco. Os critérios de inclusão foram: artigos científicos que apresentassem experiências de avaliação do desempenho do perfil de graduação, diplomas ou diplomas universitários, publicados entre 2009 e 2019. Foram identificadas cinco tendências de avaliação do desempenho do perfil de graduação: a) coerência entre os planos de estudos e instrumentos de avaliação de sujeitos com o perfil de graduação; b) ao final dos estudos universitários; c) progressivo durante o treinamento; d) progressivo e ao final dos estudos; e) avaliação por graduados e empregadores. Juntos, eles mostram contribuições significativas em termos de estratégias, instrumentos, partes interessadas e resultados que abrem perspectivas de pesquisa e desenvolvimento. Conclui-se que é necessário implementar um sistema progressivo, abrangente e participativo para avaliar a obtenção do perfil de graduação nos graus universitários, com base no conhecimento, na experiência anterior e nos desafios colocados à universidade.

Palavras-chave: avaliação, diploma universitário, obtenção do perfil de graduação.

Fecha Recepción: Enero 2020

Fecha Aceptación: Julio 2020 


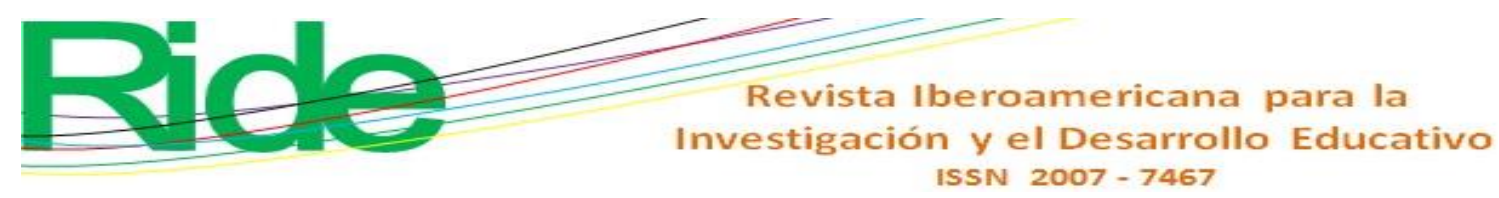

\section{Introducción}

El estudiante universitario tiene la expectativa de formarse como un profesional competente para insertarse en el campo laboral y social. Deposita su confianza en el sistema de enseñanza como dispositivo de colocación social, por lo que es un imperativo ético de la formación universitaria el asegurar la calidad de la formación en todas sus dimensiones, como persona y profesional, para su futuro desempeño laboral (Muñoz, Latrach, González y Araya, 2010, p. 78; Villa y Poblete, 2007, p. 11). Sin embargo, al egresar y postular a un trabajo, "generalmente se enfrenta a un escenario de mayor competencia, porque la oferta de graduados es más amplia, debido a la masiva expansión de la educación superior en el mundo" (Villarroel y Bruna, 2019, p. 493).

A nivel mundial existen diversas investigaciones y evaluaciones sobre la calidad de los profesionales que egresan de las universidades (Barrera, 2009; Cevallos y Rosales, 2019; Centro Interuniversitario de Desarrollo [Cinda], 2017; Izquierdo y Loarte, 2014; Maldonado y Vidal, 2015; Olivos, Voisin y Fernández, 2015). Los egresados deben evidenciar el logro del perfil de egreso en el grado que oferta la universidad, y estar preparados para responder a las exigencias cambiantes del mercado laboral y de la sociedad; por lo que "uno de los mayores desafíos es aplicar métodos de evaluación pertinentes, respondiendo al perfil de egreso comprometido y a las necesidades del mundo del trabajo" (Villarroel y Bruna, 2019, p. 496).

En este contexto, la evaluación en la educación superior se sitúa en el centro neurálgico de los procesos de formación y de la ejecución curricular; cumple una función pedagógica y social, útil para los estudiantes, docentes, la institución y la sociedad, porque permite conocer y valorar si el estudiante ha alcanzado el nivel apropiado para merecer una promoción, y si es competente para desempeñarse como profesional (Castillo y Cabrerizo, 2009; Champin, 2014). En palabras de Cano (2008), la evaluación se halla en la "encrucijada" didáctica, en el sentido de que es efecto pero a la vez es causa de los aprendizajes (p. 9).

Aunque su historia formal es relativamente reciente: sus inicios se remontan a finales del siglo XIX y principios del XX, pasando por las etapas pre y postyleriana (Castillo y Cabrerizo, 2009; Pimienta, 2012), la concepción teórica y metodológica de la evaluación en educación ha evolucionado notablemente a lo largo de los años. 


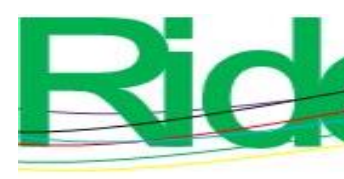

\section{Revista Iberoamericana para la Investigación y el Desarrollo Educativo ISSN 2007 - 7467}

En la actualidad, muchos autores coinciden en que la evaluación educativa en general consiste en recoger y analizar información fiable del objeto evaluado, emitir juicios de valor, a partir de los cuales tomar las decisiones pertinentes de reajuste y mejoramiento (Castillo y Cabrerizo, 2009, p. 15-17; Mateo, 2005, p. 36; Pimienta, 2012, p. 52; Sepúlveda, Opazo y Díaz, 2018, p. 38). Debe ser sistemática, integral, flexible, participativa, continua, entre otras características.

La evaluación tiene una estructura conceptual y debe responder a ciertos aspectos comunes: los contenidos (qué evaluar), los propósitos y funciones (para qué evaluar), el momento (cuándo evaluar), los procedimientos (cómo evaluar), los instrumentos (con qué evaluar) y los ejecutores o participantes (quiénes evalúan), cuyas particularidades dependen de los enfoques educativos y curriculares asumidos por las instituciones universitarias (Castillo y Cabrerizo, 2009, p. 21; Tejada y Ruiz, 2016, p. 28).

Desde los años 90, se plantearon diversos enfoques y referentes que han guiado las reformas curriculares en la educación superior en diversas latitudes, entre ellos, el socioconstructivismo, la perspectiva de la cognición y enseñanza situada, la evaluación auténtica y la formación basada en competencias (Díaz y Barroso, 2014, p. 37). Estos transversalizan y orientan la concepción y concreción curricular, por lo tanto, orientan la concepción y procedimientos de la evaluación en sus diversos ámbitos y tipos, como en la evaluación del logro del perfil de egreso en los grados universitarios.

En efecto, uno de los enfoques actuales es la evaluación auténtica centrada en el desempeño, con actividades y aprendizajes situados en el contexto (Díaz, 2005). Esta permite relacionar las clases con situaciones de la vida diaria y profesional, creando un vínculo entre lo que se aprende y su uso para la resolución de problemas cotidianos (Villarroel y Bruna, 2019, p. 496). Aquí prevalece la evaluación como proceso consustancial al aprendizaje, retroalimentador, con un rol diagnóstico y formativo más que sumativo (Ahumada, 2005, p. 18; Brown, 2015, p. 5).

Afín a este enfoque, la evaluación formativa, una de las más aceptadas internacionalmente en la educación superior (López, 2010, p. 161), se orienta hacia la mejora de los procesos de aprendizaje y formación de los estudiantes, por lo que las decisiones a tomar pueden referirse a la reestructuración de los contenidos, la reconceptualización de las metodologías didácticas o la intervención para mejorar el clima institucional (Pimienta, 2012, p. 54.) 


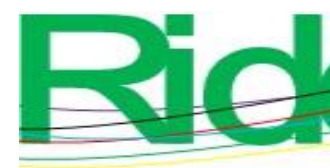

Revista Iberoamericana para la Investigación y el Desarrollo Educativo

ISSN 2007 - 7467

Existe concordancia entre los planteamientos de la evaluación auténtica, la evaluación formativa y la evaluación de competencias debido principalmente al carácter contextual y situado de estos posicionamientos pedagógicos (Sánchez, 2014, p. 26).

La evaluación de competencias es "un proceso de recogida de evidencias y de formulación de valoraciones sobre la medida y la naturaleza del progreso del estudiante, según unos resultados de aprendizaje esperados" (Valverde, Revuelta y Fernández, 2012, p. 51). En el modelo socioformativo se entiende como "una valoración sistemática del desempeño de los estudiantes, por medio de la comparación entre los criterios y las evidencias que muestran el grado de dominio que se posee en torno a una actuación determinada ante problemas pertinentes del contexto" (Tobón, Pimienta y García, 2010, p. 122-123).

Tobón (2013) resalta la valoración como un "proceso de retroalimentación y reflexión para el desarrollo y mejoramiento de las competencias, teniendo en cuenta el diagnóstico, el seguimiento continuo y criterios consensuados, a partir del cual se toman decisiones sobre estrategias docentes, estrategias de aprendizaje, recursos, políticas institucionales" (p. 321). Posteriormente, plantea lo siguiente:

La evaluación socioformativa es un proceso de diagnóstico, retroalimentación y apoyo continuo a las personas, equipos, organizaciones y comunidades para que aprendan a resolver problemas del contexto retadores, mejoren en su actuación y desarrollen el talento necesario para la sociedad del conocimiento, mediante la autoevaluación, coevaluación y heteroevaluación, teniendo como base la elaboración de productos (evidencias) e indicadores (o instrumentos) que posibiliten la metacognición, a través del trabajo colaborativo y el pensamiento complejo (Tobón, 2017, p. 17).

Esta definición resulta muy potente cuando se piensa en la evaluación del logro del perfil de egreso en los grados universitarios.

Como ha quedado patente, la concepción de la evaluación en educación ha evolucionado significativamente: de la evaluación educativa y del aprendizaje en general a la evaluación auténtica, formativa y de competencias. "Ha pasado a ser concebida como un procedimiento de asesoramiento, regulación y reorientación, pretende un seguimiento formativo que conlleva una labor pedagógica de ayuda continua" (Castillo y Cabrerizo, 2009, p.2). Asimismo, su ámbito de aplicación es cada vez mayor, ya no solo los aprendizajes, sino 


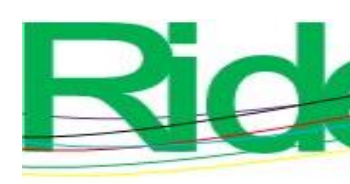

\section{Revista Iberoamericana para la Investigación y el Desarrollo Educativo ISSN 2007 - 7467}

también los programas, la docencia, los currículos, las instituciones educativas y los sistemas educativos nacionales pueden ser sometidos a este proceso (Mateo, 2005, pp. 48-275).

Por otro lado, es necesario considerar la interrelación entre la evaluación y el currículo en los sistemas educativos institucionales y nacionales en todos los niveles educativos. Desde el ámbito de la evaluación, se ubica la evaluación del currículo, sus componentes, ejecución y resultados. En este proceso se encuentra la evaluación del perfil de egreso y de su logro en los grados universitarios, área que nos ocupa en el presente estudio.

La concepción y evaluación del perfil de egreso está en función del modelo curricular asumido por los grados universitarios. Por lo que es necesario tener en cuenta los cambios e innovaciones que se han implementado.

En el contexto internacional, a partir de la Declaración de Bolonia y del proyecto Tuning-América Latina se pone en marcha una serie de innovaciones a nivel macro y microcurricular en las instituciones de educación superior (Cinda, 2017, p. 19). Los programas de pregrado de muchas universidades, en diferentes países, han transitado hacia un modelo basado en competencias, rediseñando a través de nuevos perfiles académicoprofesionales (Carrera, Lara y Madrigal, 2019; Villa y Poblete, 2007).

Considerando la evaluación como parte del currículo, "resulta lógico deducir que si el modelo curricular se desplazó hacia uno basado en competencias, la evaluación debe seguir la misma línea" (Champin, 2014, p. 566). Sin embargo, una de las cuestiones de mayor preocupación académica y científica en muchas universidades es que, a pesar de que se tiene un currículo por competencias, el proceso de evaluación sigue siendo, predominantemente, de conocimientos y sin el carácter procesual que debiera caracterizar la práctica evaluativa en este enfoque. Así pues, la evaluación en educación superior sigue ligada a disciplinas, materias y asignaturas, con poca relación con la evaluación del avance o logro del perfil de egreso (Möller y Gómez, 2014; Morales y Zambrano, 2016, p. 11; Tejada y Ruiz, 2016, p. 22).

Al abordar la evaluación del logro del perfil de egreso, surgen varias interrogantes: ¿cómo evaluar? ¿quiénes deben evaluar?, ¿cuándo evaluar, durante el proceso formativo o al final?, entre otras. Se trata de inquietudes que han motivado el presente estudio, considerando que "si la evaluación de los aprendizajes es uno de los aspectos más desafiantes que enfrenta todo docente e institución dedicada a la formación de personas, un reto aún mayor constituye la evaluación del logro de los perfiles de egreso" (Cinda, 2017, p. 19). 


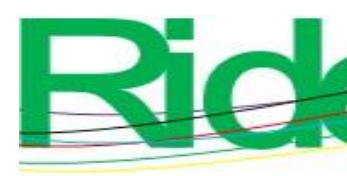

Revista Iberoamericana para la Investigación y el Desarrollo Educativo

ISSN 2007 - 7467

Al respecto, es necesario analizar algunas dificultades planteadas por diversos autores. "No se tiene un conocimiento exacto del nivel potencial de desempeño laboral del egresado, en versión del propio egresado, la universidad; y del empleador o empresa, interesada en incorporar al nuevo profesional” (Izquierdo y Loarte, 2014, p. 46). "Los cambios realizados en las instituciones de educación superior han sido insuficientes, en tanto no aseguran el seguimiento de trayectorias hacia los perfiles de egreso declarados" (Morales y Zambrano, 2016, p. 11).

Estos planteamientos exigen revisar la concepción y tratamiento de los perfiles de egreso, teniendo en cuenta que las universidades, por su autonomía, determinan el perfil de egreso de los estudiantes y lo declaran en sus documentos oficiales (Ortiz, Venegas y Espinoza, 2015, p. 71).

El perfil de egreso es concebido como el conjunto de conocimientos, habilidades, valores y sentimientos a desarrollar por los estudiantes durante su proceso de formación, el cual habrá internalizado al culminar sus estudios universitarios. Para Hawes (citado en González, Mortigo y Berdugo, 2014), el concepto de perfil profesional se define como un “conjunto de rasgos y capacidades que, certificadas apropiadamente por quien tiene la competencia jurídica para ello, permiten que alguien sea reconocido por la sociedad como 'tal' profesional" (p. 170). En el enfoque de formación basada en competencias, suele plantearse como las competencias que debe lograr o mostrar un egresado para enfrentar su ejercicio profesional (Ceballos, Ceballos, Cocca y Alfonso, 2015; Cinda, 2017).

En este sentido, el perfil de egreso o profesional es "el punto de convergencia entre la formación y la sociedad" (Carrera et al., 2019, p. 1023). Constituye el elemento direccional, la estructura sobre la cual se debe diseñar el plan de estudios y la evaluación (Champin, 2014, p. 570).

En el modelo curricular por competencias, que en la actualidad es la tendencia prevalente en los grados universitarios, el perfil de egreso se materializa en competencias genéricas o transversales y en competencias específicas o profesionales. Las competencias específicas son las que están íntimamente ligadas a las disciplinas o áreas de conocimiento que distinguen una profesión de otra; las competencias generales o transversales son comunes a la mayoría de las profesiones, por lo que rebasan los límites de las disciplinas y deben desarrollarse a través de todo el mapa curricular (Jiménez, Gutiérrez y Hernández, 2019, p. 92; Villa y Poblete, 2011, p. 36) 


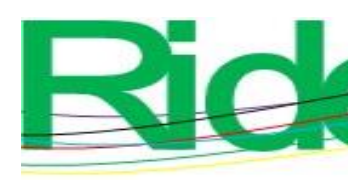

Revista Iberoamericana para la Investigación y el Desarrollo Educativo

ISSN 2007 - 7467

Los rasgos y exigencias de la evaluación del logro del perfil de egreso comparten con los de evaluación de competencias en tanto que están diseñadas y materializadas en competencias genéricas o específicas en la formación universitaria, sobre todo en el qué y cómo evaluar. En ambos casos se exige utilizar una diversidad de instrumentos y a implicar a diferentes agentes. Es necesario la multivariedad de métodos e instrumentos que permita la triangulación de la información y evidencias del objeto o sujeto evaluado, lo que facilita la toma de decisión para mejorar y asegurar el logro de las competencias (Morales y Zambrano 2016, p. 12).

Si bien existe una diversidad de técnicas e instrumentos para la evaluación de las competencias, como los protocolos de observación, entrevistas, simulaciones, escalas estimativas, rúbricas o matrices de valoración, portafolios de evidencias, los mapas conceptuales, pautas de desempeño, resolución de problemas, estudio de casos, trabajo en equipo, exámenes escritos (Cano, 2008, p. 10; Diaz y Barroso, 2014, p. 42; Pimienta, 2012, p. 47; Sepúlveda et al., 2018, p. 38), si bien existe esta diversidad, como se decía, se carece de instrumentos de evaluación coherentes y pertinentes para evaluar las habilidades o competencias declaradas en los perfiles de egreso (Möller y Gómez, 2014; Morales y Zambrano, 2016; Villarroel y Burna, 2019); aunque pueden ser adecuados o adaptados para cumplir este propósito, como muestran varias experiencias de evaluación del logro del perfil de egreso en diversos grados universitarios.

Las universidades en el contexto internacional han implementado innovaciones curriculares en el diseño de los programas al incorporar nuevos enfoques y metodologías, pero ha faltado una evaluación que evidencie el logro del perfil de egreso (Carrera et al., 2019, pp. 1021-1022). El propósito central de la evaluación del perfil de egreso y su logro debiera ser la mejora continua tanto de los procesos formativos en general como de los procesos individuales de aprendizaje y desarrollo de competencias, debe ser un ciclo permanente (Cinda, 2017, p. 34).

Ante esta situación problemática, se planteó el siguiente objetivo: analizar las principales tendencias y desafíos respecto a la evaluación del logro del perfil de egreso en diversos grados universitarios, según las experiencias publicadas en artículos científicos durante el periodo 2009-2019. 


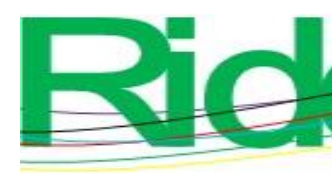

Revista Iberoamericana para la Investigación y el Desarrollo Educativo ISSN $2007-7467$

\section{Método}

Se realizó un estudio descriptivo e interpretativo con base en el metaanálisis documental de publicaciones identificadas en las siguientes bases de datos: Google Scholar, Scielo, Dialnet, Fuente Académica Plus y Ebsco. Los criterios de inclusión fueron: artículos científicos que presentaran experiencias de evaluación del logro del perfil de egreso, grados universitarios diversos, publicados dentro del periodo 2009-2019. Las palabras claves empleadas fueron: evaluación, logro del perfil de egreso, grado universitario. En primer lugar, se analizó el título y resumen según los criterios de inclusión; luego se accedió al texto completo para su análisis en una matriz en el programa Excel.

A partir de lo anterior, se analizaron 21 artículos científicos, que fueron agrupados en cinco tendencias de evaluación del logro del perfil de egreso: a) coherencia entre plan de estudios e instrumentos de evaluación de asignaturas con el perfil de egreso; $b$ ) progresiva durante la formación; $c$ ) al final de los estudios universitarios; $d$ ) progresiva y al final de los estudios, y e) por egresados y empleadores. En cada una de éstas se analizaron las siguientes variables: número de publicaciones, grados universitarios, competencias del perfil de egreso evaluados (genéricas o transversales, específicas o profesionales y específicas disciplinares), muestra, instrumentos de evaluación y resultados. Con base en ello se identificaron los aportes, debilidades y desafíos que pueden servir para la implementación de políticas y estrategias que optimicen la evaluación del logro del perfil de egreso en los grados universitarios.

\section{Resultados}

Se identificaron 21 publicaciones que presentan experiencias de evaluación del logro del perfil de egreso en diversos grados universitarios. Como ya se mencionó, fueron agrupadas en cinco tendencias: tres tratan acerca de la coherencia entre plan de estudios e instrumentos de evaluación de asignaturas con el perfil de egreso (14\%); tres tratan acerca de la evaluación progresiva durante la formación (14\%); dos que integran las dos primeras, progresiva y al final de los estudios (10\%); otros tres presentan experiencias de evaluación por parte de los egresados y los empleadores (14\%), y 10 corresponden a la evaluación al final de los estudios universitarios (48 \%), como puede observarse en las tablas 1 y 2. 


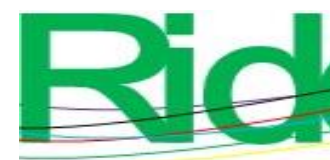

Revista Iberoamericana para la Investigación y el Desarrollo Educativo ISSN 2007 - 7467

Tabla 1. Tendencias en la evaluación del logro del perfil de egreso

\begin{tabular}{|c|c|c|c|c|}
\hline Tendencias & Autor & País & $\begin{array}{l}\text { Grados/Tit } \\
\text { ulaciones }\end{array}$ & $\begin{array}{l}\text { Tipo de competencias del } \\
\text { perfil de egreso evaluadas }\end{array}$ \\
\hline \multirow{3}{*}{$\begin{array}{l}\text { Coherencia } \\
\text { entre plan de } \\
\text { estudios e } \\
\text { instrumentos } \\
\text { de } \\
\text { evaluación } \\
\text { con el perfil } \\
\text { de egreso }\end{array}$} & $\begin{array}{l}\text { Möller y Gómez } \\
\text { (2016) }\end{array}$ & Chile & Educación & $\begin{array}{l}\text { Correspondencia entre } \\
\text { instrumentos de evaluación } \\
\text { y perfil de egreso }\end{array}$ \\
\hline & $\begin{array}{l}\text { Arribas, Manrique } \\
\text { y Tabernero } \\
(2016)\end{array}$ & España & Educación & $\begin{array}{l}\text { Correspondencia entre } \\
\text { instrumentos de evaluación } \\
\text { y competencias del perfil } \\
\text { de egreso }\end{array}$ \\
\hline & Ortiz et al. (2015) & Chile & Odontología & $\begin{array}{l}\text { Correspondencia entre } \\
\text { asignaturas del plan de } \\
\text { estudios e instrumentos de } \\
\text { evaluación y perfil de } \\
\text { egreso }\end{array}$ \\
\hline \multirow[t]{3}{*}{ Progresiva } & $\begin{array}{l}\text { Carrera et al. } \\
(2019)\end{array}$ & México & $\begin{array}{l}\text { Intervención } \\
\text { Educativa }\end{array}$ & Competencia profesional \\
\hline & $\begin{array}{l}\text { Muñoz M. y } \\
\text { Martínez C.(2016) }\end{array}$ & Chile & $\begin{array}{l}\text { Ingeniería } \\
\text { Civil }\end{array}$ & $\begin{array}{l}\text { Competencias generales y } \\
\text { profesionales }\end{array}$ \\
\hline & $\begin{array}{l}\text { Jiménez, } \\
\text { Martínez, } \\
\text { Sánchez, Juárez y } \\
\text { Paredes (2009) }\end{array}$ & España & $\begin{array}{l}\text { Ingeniería } \\
\text { Informática }\end{array}$ & $\begin{array}{l}\text { Competencias generales y } \\
\text { específicas }\end{array}$ \\
\hline \multirow[t]{2}{*}{$\begin{array}{l}\text { Progresiva y } \\
\text { fin de carrera }\end{array}$} & $\begin{array}{l}\text { Ampuero et al. } \\
\text { (2017) }\end{array}$ & Chile & $\begin{array}{l}\text { Ingeniería, } \\
\text { Educación y } \\
\text { Salud }\end{array}$ & $\begin{array}{l}\text { Siete con enfoque de } \\
\text { competencias, dos por } \\
\text { objetivos, cinco por } \\
\text { resultados de aprendizaje y } \\
\text { competencias }\end{array}$ \\
\hline & $\begin{array}{l}\text { Leiva e Iglesias } \\
\text { (2017) }\end{array}$ & Chile & Educación & $\begin{array}{l}\text { Competencias genéricas, } \\
\text { específicas disciplinares y } \\
\text { profesionales específicas }\end{array}$ \\
\hline
\end{tabular}




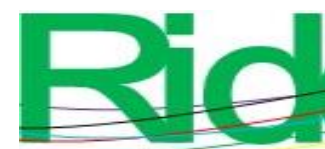

Revista Iberoamericana para la

Investigación y el Desarrollo Educativo

ISSN 2007 - 7467

\begin{tabular}{|l|l|l|l|l|}
\hline $\begin{array}{l}\text { Evaluación } \\
\text { por }\end{array}$ & $\begin{array}{l}\text { Maldonado y } \\
\text { egresados y } \\
\text { empleadores }\end{array}$ & $\begin{array}{l}\text { Clivos } \text { et al. } \\
(2015)\end{array}$ & México & Educación \\
\cline { 2 - 5 } & Médica & $\begin{array}{l}\text { Competencias } \\
\text { profesionales }\end{array}$ \\
\cline { 2 - 5 } & $\begin{array}{l}\text { Cevallos y } \\
\text { ocupacionales, humanas y } \\
\text { de mercado }\end{array}$ \\
& Rosales (2019) & Ecuador & Educación & $\begin{array}{l}\text { Competencias } \\
\text { profesionales }\end{array}$ \\
\hline
\end{tabular}

Fuente: Elaboración propia 
Tabla 2. Tendencias en la evaluación del logro del perfil de egreso

\begin{tabular}{|c|c|c|c|c|}
\hline Tendencia & Autor & País & Grado/Titulación & $\begin{array}{c}\text { Tipo de competencia } \\
\text { del perfil de egreso } \\
\text { evaluada }\end{array}$ \\
\hline \multirow[t]{8}{*}{$\begin{array}{l}\text { Evaluación } \\
\text { al final de } \\
\text { los estudios }\end{array}$} & $\begin{array}{l}\text { Álvarez y De } \\
\text { Prada (2018) }\end{array}$ & España & $\begin{array}{l}\text { Administración y } \\
\text { Dirección de } \\
\text { Empresas y } \\
\text { Turismo }\end{array}$ & $\begin{array}{l}\text { Competencias } \\
\text { genéricas }\end{array}$ \\
\hline & Barrera (2009) & Chile & Pedagogía & $\begin{array}{l}\text { Competencias } \\
\text { generales y específicas }\end{array}$ \\
\hline & $\begin{array}{l}\text { López, Molina, } \\
\text { Rebolledo y } \\
\text { Suárez (2017) }\end{array}$ & Chile & Enfermería & $\begin{array}{l}\text { Competencias } \\
\text { profesionales y } \\
\text { genéricas }\end{array}$ \\
\hline & $\begin{array}{l}\text { Jiménez, } \\
\text { Machado, Caso } \\
\text { y Arrayales } \\
\text { (2019) }\end{array}$ & México & $\begin{array}{l}\text { Actividad Física y } \\
\text { del Deporte }\end{array}$ & $\begin{array}{l}\text { Competencias } \\
\text { profesionales y } \\
\text { genéricas }\end{array}$ \\
\hline & $\begin{array}{l}\text { Flores y Barajas } \\
(2018)\end{array}$ & México & $\begin{array}{l}\text { Técnicos superiores } \\
\text { universitarios en } \\
\text { Procesos } \\
\text { Industriales }\end{array}$ & $\begin{array}{l}\text { Competencias } \\
\text { generales y específicas }\end{array}$ \\
\hline & $\begin{array}{l}\text { Murillo y } \\
\text { Trujillo (2010) }\end{array}$ & $\begin{array}{l}\text { Colombi } \\
\text { a }\end{array}$ & Medicina & $\begin{array}{l}\text { Competencias } \\
\text { profesionales }\end{array}$ \\
\hline & $\begin{array}{l}\text { Izquierdo y } \\
\text { Loarte (2014) }\end{array}$ & Ecuador & $\begin{array}{l}\text { Ingeniería } \\
\text { Comercial }\end{array}$ & $\begin{array}{l}\text { Competencias } \\
\text { generales y específicas }\end{array}$ \\
\hline & $\begin{array}{l}\text { Jiménez et al. } \\
\text { (2019) }\end{array}$ & México & $\begin{array}{l}\text { Ingeniería y } \\
\text { ciencias físico } \\
\text { matemáticas, } \\
\text { ciencias médico } \\
\text { biológicas y } \\
\text { ciencias sociales y } \\
\text { administrativas }\end{array}$ & $\begin{array}{l}\text { Competencias } \\
\text { transversales }\end{array}$ \\
\hline
\end{tabular}




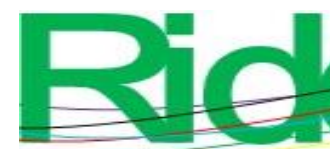

Revista Iberoamericana para la Investigación y el Desarrollo Educativo ISSN 2007 - 7467

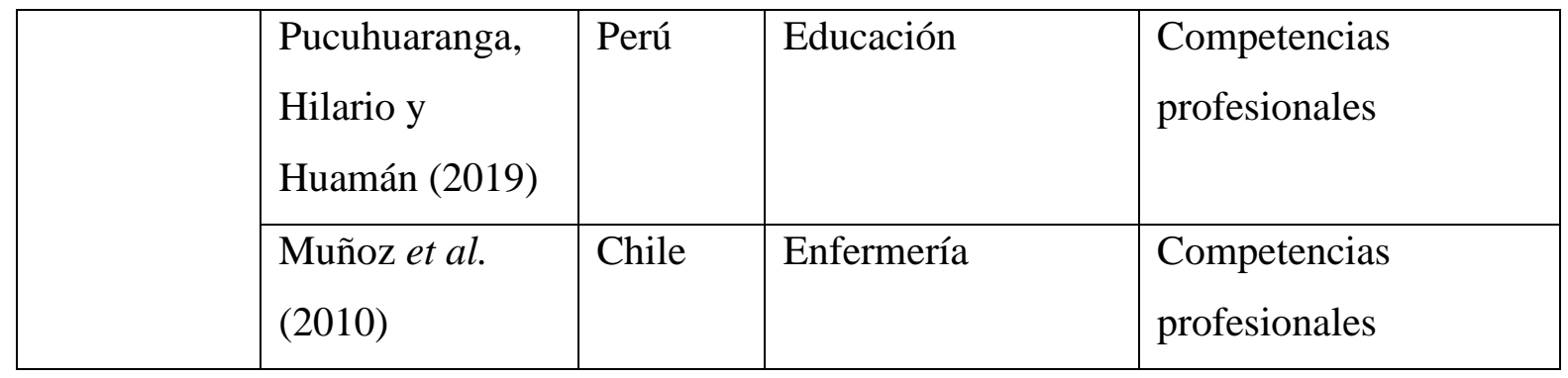

Fuente: Elaboración propia

En cuanto a los grados universitarios, como puede identificarse en las tablas 1 y 2 , nueve publicaciones presentan resultados en educación (31\%), siete en salud (24\%), tres en ingeniería (10\%), dos en administración, ingeniería informática, actividad física y deporte, cuatro en otras. Asimismo, son procedentes de universidades ubicadas en distintos países: nueve en Chile (43\%), cinco en México (24\%), tres en España (14\%), y las otras cuatro en Ecuador, Perú y Colombia. En cuanto al aspecto de la competencia del perfil de egreso, en estas experiencias se han evaluado las competencias generales o transversales, las específicas o profesionales declaradas en el perfil de egreso de los grados respectivos. 


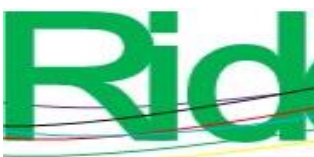

Revista Iberoamericana para la Investigación y el Desarrollo Educativo ISSN 2007 - 7467

Tabla 3. Instrumentos, muestra y resultados de evaluación del logro del perfil de egreso

\begin{tabular}{|c|c|c|c|}
\hline $\begin{array}{c}\text { Tendencia } \\
\text { s }\end{array}$ & $\begin{array}{c}\text { Instrument } \\
\text { os }\end{array}$ & Muestra & Resultados resaltantes \\
\hline \multirow{3}{*}{$\begin{array}{l}\text { Coherencia } \\
\text { entre plan } \\
\text { de estudios } \\
\text { e } \\
\text { instrument } \\
\text { os de } \\
\text { evaluación } \\
\text { con el } \\
\text { perfil de } \\
\text { egreso }\end{array}$} & $\begin{array}{l}\text { Entrevistas, } \\
\text { grupos } \\
\text { focales y } \\
\text { análisis } \\
\text { documental }\end{array}$ & $\begin{array}{l}\text { Profesores } \\
\text { que } \\
\text { imparten la } \\
\text { asignatura }\end{array}$ & $\begin{array}{l}\text { En todos los casos hay algún nivel de } \\
\text { correspondencia en cuanto a los ámbitos del } \\
\text { desempeño, los verbos y las dimensiones que } \\
\text { aborda la competencia o habilidad y los indicadores } \\
\text { de evaluación. }\end{array}$ \\
\hline & $\begin{array}{l}\text { Cuestionario } \\
\text { estructurado } \\
\text { de } 63 \text { items }\end{array}$ & $\begin{array}{l}199 \\
\text { alumnos, } 67 \\
\text { egresados y } \\
53 \\
\text { profesores }\end{array}$ & $\begin{array}{l}\text { Todos los grupos señalan la participación en clase, } \\
\text { los informes o trabajos escritos y los ensayos a } \\
\text { partir de textos escritos y material audiovisual como } \\
\text { instrumentos de evaluación con altos o muy altos } \\
\text { niveles de coherencia para el desarrollo de las } \\
\text { competencias. }\end{array}$ \\
\hline & $\begin{array}{l}\text { Encuesta de } \\
\text { cinco ítems }\end{array}$ & $\begin{array}{l}30 \\
\text { académicos } \\
\text { (docentes) }\end{array}$ & $\begin{array}{l}91 \% \text { de las competencias del perfil del egresado se } \\
\text { desarrollan con los estudiantes en las asignaturas } \\
\text { correspondientes. Se utilizan metodologías } \\
\text { educativas-evaluativas que contribuyen al logro de } \\
\text { las competencias. }\end{array}$ \\
\hline \multirow[t]{2}{*}{ Progresiva } & $\begin{array}{l}\text { Observación } \\
\text {, entrevista } \\
\text { y encuesta }\end{array}$ & $\begin{array}{l}50 \\
\text { estudiantes } \\
\text { y } 10 \\
\text { profesores }\end{array}$ & $\begin{array}{l}\text { La principal barrera para el logro del perfil de } \\
\text { egreso es la docencia, ya que los alumnos dominan } \\
\text { los contenidos pero no asumen una postura reflexiva } \\
\text { respecto a su proceso de formación, a los logros } \\
\text { obtenidos y sobre todo a su papel como } \\
\text { transformador social. }\end{array}$ \\
\hline & $\begin{array}{l}\text { Escala tipo } \\
\text { Likert para } \\
\text { cada } \\
\text { resultado de } \\
\text { aprendizaje }\end{array}$ & $\begin{array}{l}62 \% \text { de } \\
\text { estudiantes } \\
\text { de primer } \\
\text { año y } 100 \% \\
\text { de tercer } \\
\text { año }\end{array}$ & $\begin{array}{l}\text { En las habilidades personales y profesionales se } \\
\text { observa una mejor percepción de los niveles de } \\
\text { logro en el segundo hito evaluativo, sin embargo, en } \\
\text { las habilidades interpersonales, en el segundo hito } \\
\text { evaluativo, los estudiantes se perciben en mayor } \\
\text { porcentaje en los niveles de logro tres y cuatro. }\end{array}$ \\
\hline
\end{tabular}




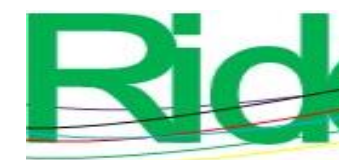

Revista Iberoamericana para la Investigación y el Desarrollo Educativo ISSN 2007 - 7467

\begin{tabular}{|c|c|c|c|}
\hline & $\begin{array}{l}\text { Entrevista } \\
\text { personal, } \\
\text { examen } \\
\text { teórico, } \\
\text { informe } \\
\text { técnico } \\
\text { parcial y } \\
\text { final de las } \\
\text { prácticas }\end{array}$ & $\begin{array}{l}\text { Profesores y } \\
\text { estudiantes }\end{array}$ & $\begin{array}{l}\text { Como resultado se da una calificación numérica de } \\
\text { acuerdo a la legislación vigente además de un nivel } \\
\text { de logro para cada una de las competencias } \\
\text { generales y específicas, así como un nivel de logro } \\
\text { de los bloques de competencias generales y de } \\
\text { competencias específicas de la asignatura. Se } \\
\text { presenta la Ficha de evaluación de competencias del } \\
\text { estudiante en el Título de Grado }\end{array}$ \\
\hline \multirow[t]{2}{*}{$\begin{array}{l}\text { Progresiva } \\
\text { y fin de } \\
\text { carrera }\end{array}$} & Cuestionario & $\begin{array}{l}\text { Jefes de } \\
\text { carrera }\end{array}$ & $\begin{array}{l}\text { En ingeniería: en dos carreras los estudiantes habían } \\
\text { adquirido la capacidad de trabajo autónomo, trabajo } \\
\text { en equipo y capacidad de emprender; entre el } \\
\text { segundo y sexto semestre. En educación, evidencian } \\
\text { un buen nivel de avance en el logro de } \\
\text { competencias y que el trabajo de tutorías grupales o } \\
\text { individuales refuerza el logro. En salud: han } \\
\text { alcanzado un buen nivel de logro de competencias. }\end{array}$ \\
\hline & $\begin{array}{l}\text { Rúbricas } \\
\text { analíticas y } \\
\text { encuestas }\end{array}$ & $\begin{array}{l}\text { Tutor, } \\
\text { profesor } \\
\text { mentor y } \\
\text { evaluador } \\
\text { externo }\end{array}$ & $\begin{array}{l}89 \% \text { de los profesores en formación logran un } \\
\text { desempeño competente-destacado y solo un } 11 \% \\
\text { logra un desempeño básico-insatisfactorio. En las } \\
\text { competencias } 1 \text { y } 7 \text { mayor grado de satisfacción en } \\
\text { los egresados. }\end{array}$ \\
\hline $\begin{array}{l}\text { Evaluación } \\
\text { por } \\
\text { egresados } \\
\text { y } \\
\text { empleador } \\
\text { es }\end{array}$ & $\begin{array}{l}\text { Encuesta } \\
\text { por correo, } \\
\text { con una } \\
\text { escala de } \\
\text { respuesta de } \\
\text { cero a siete. }\end{array}$ & $\begin{array}{l}31 \\
\text { egresados }\end{array}$ & $\begin{array}{l}\text { En el dominio asistencial, } 16 \text { de los } 25 \text { indicadores } \\
\text { han sido evaluados por sobre } 75 \% \text { de los egresados } \\
\text { en grado alto. En Administración, aparece como el } \\
\text { más débil dentro de la formación: Reconocen } \\
\text { deficiencias en herramientas de administración y } \\
\text { gestión de laboratorio. En el dominio Educación, } \\
\text { medianamente satisfactorios. En Investigación, los } \\
\text { egresados manifiestan un logro alto de estas, en } \\
\text { porcentajes superiores a } 90 \% \text {. }\end{array}$ \\
\hline
\end{tabular}




\begin{tabular}{|c|c|c|}
\hline $\begin{array}{l}\text { Entrevista } \\
\text { abierta a } \\
\text { egresados } \\
\text { contratados }\end{array}$ & $\begin{array}{l}19 \\
\text { empleadores }\end{array}$ & $\begin{array}{l}\text { Las zonas de oportunidad de institucionalización del } \\
\text { saber se ubican en tres ejes: competencias } \\
\text { profesionales, de formación humana y académicas. } \\
\text { Como parte de los resultados, se identificó una } \\
\text { necesidad de elevación del nivel de certificación de } \\
\text { lengua, especialización de FOS (negocios y } \\
\text { turismo), orientación a educación básica y media } \\
\text { superior, relaciones públicas y comunicación y el } \\
\text { manejo de marketing. }\end{array}$ \\
\hline Encuesta & $\begin{array}{l}13 \\
\text { graduados } \\
\text { del } 2010,11 \\
\text { del } 2011 \text { y } \\
12 \text { del } 2012\end{array}$ & $\begin{array}{l}94.3 \% \text { de los graduados se encuentra empleados en } \\
\text { su esfera de actuación; de ellos, } 50 \% \text { laboran como } \\
\text { entrenadores deportivos, } 41.66 \% \text { como profesores y } \\
\text { uno labora como árbitro deportivo. Hay una buena } \\
\text { relación entre las competencias adquiridas y las } \\
\text { requeridas. }\end{array}$ \\
\hline
\end{tabular}

Fuente: Elaboración propia 


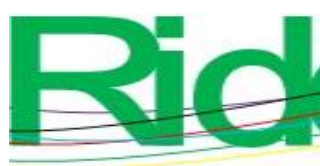

Revista Iberoamericana para la Investigación y el Desarrollo Educativo

ISSN 2007 - 7467

Tabla 4. Instrumentos, muestra y resultados de evaluación del logro del perfil de egreso en la tendencia evaluación al final de los estudios

\begin{tabular}{|c|c|c|}
\hline $\begin{array}{c}\text { Instrumento } \\
\mathrm{S}\end{array}$ & Muestra & Resultados \\
\hline $\begin{array}{l}\text { Encuesta } \\
\text { elaborada por } \\
\text { área empleo y } \\
\text { emprendimie } \\
\text { nto }\end{array}$ & $\begin{array}{l}274 \text { prácticas } \\
\text { de alumnos } \\
\text { de dos } \\
\text { titulaciones, y } \\
274 \text { tutores de } \\
\text { prácticas }\end{array}$ & $\begin{array}{l}\text { La puntuación promedio de todas las competencias } \\
\text { evaluadas es satisfactoria, pues en todos los casos es alta y } \\
\text { superior a cuatro sobre cinco; hay que exceptuar de estos } \\
\text { resultados a la creatividad, competencia que ha sido } \\
\text { evaluada como la más baja. Las puntuaciones dadas por los } \\
\text { tutores en las empresas para cualquiera de las competencias } \\
\text { analizadas son siempre más elevadas que las calificadas por } \\
\text { los alumnos. }\end{array}$ \\
\hline $\begin{array}{l}\text { Subprueba de } \\
\text { Plan Común } \\
\text { Universidad } \\
\text { (PCU) y } \\
\text { subprueba de } \\
\text { Plan Común } \\
\text { Educación } \\
\text { (PCEDUC). }\end{array}$ & $\begin{array}{l}183 \\
\text { estudiantes de } \\
\text { último } \\
\text { semestre de } \\
\text { nueve } \\
\text { programas de } \\
\text { pedagogía } \\
\text { que se } \\
\text { presentaron } \\
\text { voluntariame } \\
\text { nte }\end{array}$ & $\begin{array}{l}53 \% \text { de estudiantes alcanza un nivel de logro en los planes } \\
\text { comunes evaluados. Los estudiantes alcanzan un logro } \\
\text { regularmente insuficiente en teología y ética, mientras que } \\
\text { en desarrollo personal es menor. } 48 \% \text { de estudiantes opina } \\
\text { que fue satisfactorio y } 18 \% \text { de estudiantes expresa su } \\
\text { absoluta satisfacción. }\end{array}$ \\
\hline $\begin{array}{l}\text { Escala de } \\
\text { apreciación } \\
\text { de } \\
\text { competencias }\end{array}$ & $\begin{array}{l}45 \text { internos } \\
\text { (enfermeros) }\end{array}$ & $\begin{array}{l}\text { Alto porcentaje de los alumnos internos logran un } \\
\text { desempeño efectivo. Las competencias generales lograron } \\
\text { el mejor nivel, seguidas por la competencia asistencial }\end{array}$ \\
\hline $\begin{array}{l}\text { Prueba para } \\
\text { egresados y } \\
\text { cuestionario } \\
\text { para el } \\
\text { estudiante }\end{array}$ & $\begin{array}{l}193 \\
\text { participantes: } \\
78(40.41 \%) \\
\text { egresados y } \\
115\end{array}$ & $\begin{array}{l}\text { La mayor parte de los participantes ( } 84.97 \% \text { insuficiente, } \\
14.51 \% \text { suficiente) no alcanza a obtener un nivel de } \\
\text { suficiencia bajo los estándares establecidos por la } \\
\text { comunidad académica de la Facultad de Deportes. Los } \\
\text { puntos de corte establecidos por la comunidad académica }\end{array}$ \\
\hline
\end{tabular}




\begin{tabular}{|c|c|c|}
\hline & $\begin{array}{l}(59.58 \%) \\
\text { estudiantes de } \\
\text { octavo } \\
\text { semestre }\end{array}$ & $\begin{array}{l}\text { permitieron identificar que altas proporciones de } \\
\text { estudiantes no están alcanzando los niveles esperados al } \\
\text { terminar su formación. }\end{array}$ \\
\hline $\begin{array}{l}\text { Cuestionario } \\
\text { considerando } \\
\text { las tareas } \\
\text { durante la } \\
\text { estadía de } \\
\text { prácticas }\end{array}$ & $\begin{array}{l}153 \\
\text { estudiantes: } \\
23(2015), 50 \\
(2016) \text { y } 80 \\
\text { de la } \\
\text { generación } \\
\text { mayo-agosto } \\
2017\end{array}$ & $\begin{array}{l}\text { Un gran porcentaje está completamente satisfecho o } \\
\text { satisfecho de las competencias desarrolladas. Ninguno } \\
\text { manifestó estar insatisfechos, sin embargo, reconocen el } \\
\text { menor de los desempeños en la variable "Interpretar } \\
\text { información técnica en un segundo idioma" y en la variable } \\
\text { "Dificultad en asumir el rol de líder dentro de un grupo de } \\
\text { trabajo" }\end{array}$ \\
\hline $\begin{array}{l}\text { Una encuesta } \\
\text { con } 63 \\
\text { competencias } \\
\text { basada en el } \\
\text { proyecto } \\
\text { Tuning } \\
\text { complementa } \\
\text { da con la de } \\
\text { la Asociación } \\
\text { Colombiana } \\
\text { de Facultades } \\
\text { de Medicina }\end{array}$ & $\begin{array}{l}99 \\
\text { participantes: } \\
50.5 \% \\
\text { médicos } \\
\text { internos, } \\
10.1 \% \text { a } \\
\text { profesores } \\
\text { asignados } \\
\text { para el } \\
\text { internado, } \\
6.1 \% \text { a } \\
\text { enfermeras y } \\
33.3 \% \text { a } \\
\text { estudiantes } \\
\text { del noveno }\end{array}$ & $\begin{array}{l}\text { Con respecto a la relación entre el perfil profesional del } \\
\text { egresado con las mejor y las peor evaluadas se encontró } \\
\text { coincidencia en "Comunicar la naturaleza y severidad del } \\
\text { padecimiento", "Identificar los factores sociales" y } \\
\text { "Aprender y actualizarse permanentemente" (mejor } \\
\text { evaluadas); mientras que dentro de las peor evaluadas: } \\
\text { "Identificar y orientar programas dirigidos a comunidades } \\
\text { en relación con control de enfermedades transmitidas de } \\
\text { origen hídrico, aéreo, contaminación alimentaria por } \\
\text { vectores, "Identificar y orientar programas dirigidos a } \\
\text { comunidades en relación con pesticidas, herbicidas y } \\
\text { matamalezas" y "Trabajar en promoción y prevención con } \\
\text { adolescentes". Se encontró una tendencia preferente hacia } \\
\text { las competencias del saber y en menor grado a las del saber } \\
\text { hacer y el ser. }\end{array}$ \\
\hline
\end{tabular}




\begin{tabular}{|c|c|c|}
\hline $\begin{array}{l}\text { Encuesta para } \\
\text { egresados, } \\
\text { empleadores, } \\
\text { docentes. } \\
\text { Formato de } \\
\text { competencias } \\
\text { didácticas } \\
\text { para } \\
\text { docentes. } \\
\text { Encuesta para } \\
\text { estudiantes }\end{array}$ & $\begin{array}{l}207 \\
\text { estudiantes } \\
\text { del último } \\
\text { nivel: } 145 \text { de } \\
\text { la sede Quito } \\
\text { y } 62 \text { de la } \\
\text { sede Cuenca. } \\
\text { Organizacion } \\
\text { es sociales, } \\
\text { empresariales } \\
\text { y } \\
\text { empleadores }\end{array}$ & $\begin{array}{l}\text { A nivel formativo, las competencias genéricas alcanzadas } \\
\text { representan } 76.1 \% \text { del estándar. En promedio, las } \\
\text { competencias formativas específicas logradas representan el } \\
74.0 \% \text { del estándar: competencias formativas genéricas } \\
\text { alcanzadas: } 76.1 \% \text {; competencias formativas específicas } \\
\text { alcanzadas: } 74 \% \text { y competencias de desempeño } \\
\text { profesional alcanzadas: } 71.7 \%\end{array}$ \\
\hline $\begin{array}{l}\text { Cuestionario } \\
\text { en dos partes: } \\
\text { información } \\
\text { sociodemográ } \\
\text { fica y las } \\
\text { categorías de } \\
\text { análisis }\end{array}$ & $\begin{array}{l}1903 \text { alumnos } \\
\text { (946 mujeres } \\
\text { y } 957 \\
\text { hombres), de } \\
\text { los cuales } \\
1138 \text { fueron } \\
\text { de Ingeniería } \\
\text { y ciencias } \\
\text { físico } \\
\text { matemáticas } \\
\text { (ICFM), } 238 \\
\text { de Ciencias } \\
\text { médico } \\
\text { biológicas } \\
\text { (CMB) y } 527 \\
\text { de Ciencias } \\
\text { sociales y } \\
\text { administrativ } \\
\text { as (CSA) }\end{array}$ & $\begin{array}{l}\text { La competencia "Plan de vida y carrera de los estudiantes" } \\
\text { está ligada a una actuación autónoma. Hay diferentes grados } \\
\text { de desarrollo de la competencia "Trabajo en equipo y } \\
\text { liderazgo", más desarrollada en estudiantes de CSA y } \\
\text { menos en los de ICFM. En relación con la conciencia y } \\
\text { apertura al cambio, el estudio muestra que en la conducta y } \\
\text { valoración de diferentes actividades prevalecen roles y } \\
\text { estereotipos. }\end{array}$ \\
\hline
\end{tabular}




\begin{tabular}{|c|c|c|}
\hline $\begin{array}{l}\text { Rúbricas para } \\
\text { evaluar: } \\
\text { proyectos de } \\
\text { investigación, } \\
\text { informe de } \\
\text { tesis, } \\
\text { sesiones de } \\
\text { aprendizaje, } \\
\text { proyecto } \\
\text { educativo } \\
\text { institucional, } \\
\text { y escala de } \\
\text { actitudes } \\
\text { pedagógicas e } \\
\text { investigativas }\end{array}$ & $\begin{array}{l}76 \\
\text { estudiantes: } \\
44 \text { de } \\
\text { educación } \\
\text { inicial y } \\
32 \text { de } \\
\text { educación } \\
\text { primaria } \\
\text { (promoción } \\
\text { 2018), }\end{array}$ & $\begin{array}{l}\text { Al aplicar el modelo de evaluación del perfil de egreso, los } \\
\text { estudiantes de educación inicial y primaria, promoción } \\
2018 \text {, egresan con un nivel aceptable y destacado en la } \\
\text { competencia pedagógico-didáctica y de gestión, en tanto } \\
\text { que, en las competencias investigativas, orientadora } \\
\text { axiológica, promoción educativa, sociocultural y de } \\
\text { especialidad alcanzan un nivel aceptable. }\end{array}$ \\
\hline $\begin{array}{l}\text { Rúbrica con } \\
14 \\
\text { actividades de } \\
\text { enfermería } \\
\text { para evaluar } \\
\text { la } \\
\text { competencia } \\
\text { asistencial }\end{array}$ & $\begin{array}{l}67 \text { estudiantes } \\
\text { en diferentes } \\
\text { centros } \\
\text { hospitalarios } \\
\text { con pacientes } \\
\text { reales. }\end{array}$ & $\begin{array}{l}41 \% \text { de los estudiantes tuvo un desempeño efectivo; } 31 \% \\
\text { desempeño excepcional, y } 28 \% \text { requiere mejoramiento. El } \\
\text { sistema de evaluación fue validado, la rúbrica facilitó la } \\
\text { categorización del nivel de desempeño. Las actividades } \\
\text { donde los estudiantes lograron el desempeño con } \\
\text { porcentajes de } 95 \% \text {, considerando el desempeño efectivo y } \\
\text { el de excelencia, fueron "Utilizar principios de asepsia y } \\
\text { antisepsia" y "Aplicación de precauciones estándar". En las } \\
\text { actividades, "Elaborar objetivos", "Realizar registros" y } \\
\text { "Realizar evaluación" hay un porcentaje mayor de alumnos } \\
\text { que requiere mejoramiento. }\end{array}$ \\
\hline
\end{tabular}

Fuente: Elaboración propia 


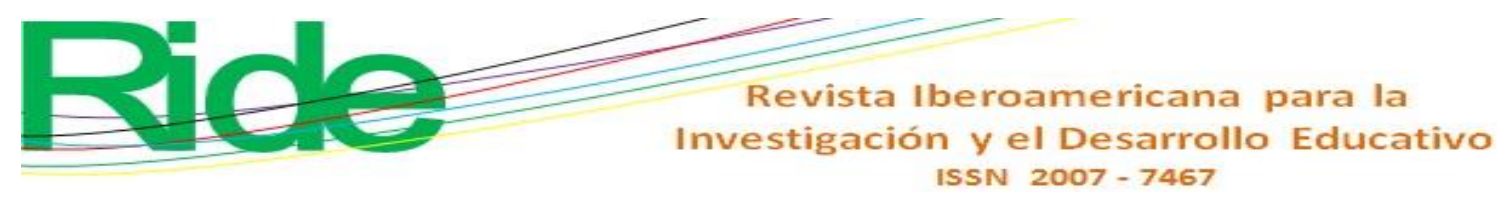

\section{Discusión}

Las experiencias de evaluación del logro del perfil de egreso de los grados universitarios presentadas en las publicaciones muestran grandes aportes y diversidad de formas de abordar. Si bien se agruparon en cinco tendencias, no tienen límites definidos entre ellas porque están interrelacionadas y son complementarias.

Como punto de partida es necesario el alineamiento o correspondencia del perfil de egreso con el plan de estudios, la enseñanza y los procedimientos de evaluación, como puede observarse en las tablas 1 y 3 . Precisamente, en la primera tendencia, Ortiz et al. (2015) encontró $91 \%$ de correspondencia entre las competencias y contenidos del plan de estudios para adquirir la competencia del perfil del egresado en el grado de Odontología. Asimismo, señalan que todas las asignaturas utilizan metodologías educativas-evaluativas que contribuyen al logro de las competencias. Los estudios de Möller y Gómez (2014) y de Arribas et al. (2016) concluyen, por su parte, que existe algún nivel de correspondencia en cuanto a los ámbitos del desempeño de las competencias con las habilidades e indicadores de evaluación; los instrumentos de evaluación como la participación en clase, los informes o trabajos escritos y los ensayos a partir de textos escritos y material audiovisual tienen altos niveles de coherencia para el desarrollo de las competencias. Estas experiencias presentan aportes muy importantes: el uso de entrevistas, cuestionarios y encuestas como instrumentos de recolección de información, aplicados a docentes, estudiantes y egresados como actores informantes para evaluar y establecer si existe la correspondencia. Desde el punto de vista técnico curricular, toda asignatura del plan de estudios debe aportar de alguna manera al avance o logro del perfil de egreso. En otras palabras, materia y meta final deben estar adecuadamente alineadas. Igualmente deben estarlo las estrategias de enseñanza aprendizaje y de evaluación aplicadas durante la formación. Esto constituye una responsabilidad y un desafío institucional para las universidades y los docentes.

La segunda tendencia corresponde a la evaluación del logro del perfil de egreso de forma progresiva durante los estudios (tablas 1 y 3). Muñoz y Martínez (2016) evaluaron a estudiantes al terminar el primer y tercer año (primer y segundo hito, el tercero es en el quinto año), a través de una escala tipo Likert para cada resultado de aprendizaje declarado en las competencias generales y específicas del perfil de egreso: en las habilidades personales y profesionales se observa una mejor percepción en el segundo hito evaluativo. Aunque puede ser discutible el uso de un solo instrumento (la escala tipo Likert) y un solo actor, el 


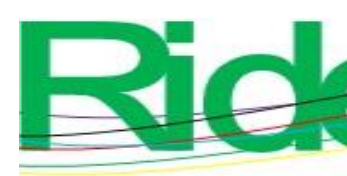

Revista Iberoamericana para la Investigación y el Desarrollo Educativo

ISSN 2007 - 7467

estudiante, quien expresa su autopercepción, es una experiencia significativa evaluar el avance de dos competencias del perfil de egreso en los primeros años de formación. En el mismo sentido, Jiménez et al. (2009) evaluaron las competencias transversales y específicas que se desarrollan a través de la asignatura, los indicadores de evaluación (desempeños), los hitos, acciones y los agentes; proponen varios instrumentos (entrevista personal, examen teórico, informe técnico parcial y final de prácticas) y una ficha de evaluación que presenta resultados en números y por niveles de logro de las competencias generales y específicas, así como de la asignatura. También Carrera et al. (2019), con un enfoque interpretativo, aplicaron la observación, la entrevista y la encuesta para recoger las percepciones de profesores y estudiantes respecto al logro del perfil de egreso con estudiantes de octavo semestre. Entre los resultados, es de destacar que de las ocho competencias evaluadas, hay varias competencias valoradas como de logro menor y una como no lograda. Como puede notarse, el aporte de estos estudios está en el uso de diversos instrumentos, actores y, sobre todo, que evalúan el avance del logro de competencias del perfil de egreso en estudiantes del primer, tercer y cuarto año, es decir, antes de que culminen sus estudios universitarios.

Por lo tanto, es necesario organizar y aplicar el diseño de un sistema de evaluación de las asignaturas que incluya no solo las competencias de ésta, sino también las competencias generales y específicas planteadas en el perfil de egreso, de tal forma que pueda evidenciarse su evaluación progresiva durante la formación, pues no se trata tanto de emitir un juicio al final del trayecto como de seguir la progresión del desarrollo de competencias (Cinda, 2017; Fernández, 2010). Esto constituye también un desafío para los grados universitarios.

Otra tendencia es la evaluación del logro del perfil de egreso al final de los estudios en diversos grados universitarios (tablas 2 y 4), en donde se agrupa la mayor cantidad de publicaciones (11). Cinco artículos describen las experiencias en contextos de la realización de las prácticas preprofesionales en la empresa (Álvarez y De Prada, 2018; Flores y Barajas, 2018) y, en el caso de salud, en los internados (López et al., 2017; Muñoz et al., 2010; Murillo y Trujillo, 2010). El uso de una variedad de instrumentos y diversos informantes, como encuestas a estudiantes y tutores de prácticas, escalas de apreciación a internos, cuestionarios a estudiantes y egresados, e incluso una rúbrica para la competencia asistencial de enfermería en centros hospitalarios, son parte de sus aportes. En esa línea, destaca el trabajo de Murillo y Trujillo (2010) por la variedad de participantes en la evaluación: médicos internos, docentes asignados para el internado, enfermeras y estudiantes del onceavo semestre, que permite la 


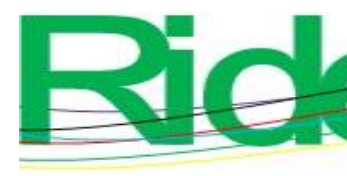

Revista Iberoamericana para la
Investigación y el Desarrollo Educativo
ISSN $2007-7467$

triangulación de datos. En cuanto a las competencias generales y específicas evaluadas en la práctica preprofesional, se informa un desempeño efectivo y satisfactorio en la mayoría de los estudiantes.

Cinco publicaciones describen experiencias de evaluación en el último ciclo o semestre de estudios: tres en educación (Barrera, 2009; Jiménez, Machado et al., 2019; Pucuhuaranga et al., 2019) y dos en ingeniería (Izquierdo y Loarte, 2014; Jiménez et al., 2019). Entre los instrumentos utilizados están las pruebas, encuestas, cuestionarios y rúbricas, aplicados a estudiantes de último semestre, pero también a egresados, y en un caso, a los empleadores. Los resultados son variados. En la mayoría de los casos hay entre 50 \% y $70 \%$ de satisfacción en cuanto al logro de las competencias generales y específicas del perfil de egreso; en pocos casos se reportan logros de nivel aceptable y destacado. Aquí resalta el trabajo de Barrera (2009), quien reporta la evaluación del plan común de universidad y de educación (competencias generales) en nueve programas de pedagogía, con un nivel de logro de $53 \%$ de estudiantes. Asimismo, resultan interesante los resultados analizados por Pucuhuaranga et al. (2019) respecto a las competencias profesionales de educación, pues hallaron un nivel aceptable y destacado en la competencia pedagógico-didáctica y de gestión, y un nivel aceptable en las competencias investigativa, orientadora axiológica, promoción educativa, sociocultural y de especialidad. Y contrario a esto, en Jiménez, Machado et al. (2019) $84.97 \%$ de los estudiantes no alcanza a obtener un nivel suficiente "bajo los estándares establecidos por la comunidad académica" (p. 136) al terminar su formación, lo cual puede ser discutible porque también participaron estudiantes del octavo semestre.

Como se puede observar en los resultados, siempre hay un grupo de estudiantes que no logra el nivel satisfactorio, o incluso habiendo logrado las competencias previstas en el perfil de egreso, puede que existan en el mercado laboral demandas no asumidas en el currículo, por lo que sea necesario plantear alguna estrategia de nivelación o incorporación. Estos estudios aportan con la diversidad de instrumentos aplicados y a partir de la participación de varios agentes, tal y como recomienda Cano (2008).

Hay otras experiencias de evaluación progresiva y al final de los estudios universitarios que integran las dos tendencias anteriores (tablas 1 y 3). El estudio presentado por Ampuero et al. (2017) constituye un aporte significativo. A través de un cuestionario aplicado a los jefes de programa de cinco carreras profesionales en Chile (vinculadas con la educación, salud e ingeniería), estos autores analizan la evaluación progresiva del logro del 


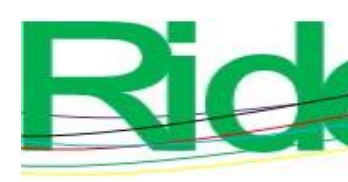

Revista Iberoamericana para la Investigación y el Desarrollo Educativo

ISSN 2007 - 7467

perfil de egreso en el itinerario del segundo al décimo semestre. Como parte de los resultados, en ingeniería, en dos carreras los estudiantes habían adquirido la capacidad de trabajo autónomo, trabajo en equipo y capacidad de emprender; entre el segundo y sexto semestre, en educación, evidencian un buen nivel de avance en el logro de competencias y en el trabajo de tutorías grupales o individuales, y en salud han alcanzado un buen nivel de logro de competencias, aunque en esta sugieren la necesidad de mayor integración de la teoría y la práctica.

Mientras que en la experiencia presentada por Leiva e Iglesias (2017) se evaluó en el logro a partir de tres niveles: evaluaciones clave (asignaturas), evaluaciones integradas (en hitos) y evaluación de las prácticas, con múltiples evaluadores: tutor, profesor, mentor y evaluador externo, cuyos resultados se procesaron utilizando la plataforma tecnológica Seprad. Al final, $89 \%$ logra un desempeño competente-destacado y solo $11 \%$ logra un desempeño básico-insatisfactorio. Los autores proponen la necesidad de implementar un sistema de aseguramiento de la calidad del logro de las competencias en la formación profesional desde el perfil de ingreso hasta el perfil de egreso. Estos estudios tienen un aporte trascendental porque la integración de la evaluación progresiva y al final de los estudios universitarios expresan la forma ideal de un sistema de evaluación de las competencias de las asignaturas y de las competencias declaradas en el perfil de egreso, y mejor aún, dentro de un sistema de aseguramiento de la calidad de la formación profesional.

La quinta tendencia de la evaluación del logro del perfil de egreso es a través de la consulta a los egresados y empleadores (tablas 1 y 3); constituye una forma necesaria para asegurar la pertinencia y coherencia externa. El trabajo de Olivos et al. (2015), con una entrevista abierta a empleadores de diversos niveles y modalidades educativas de enseñanza del francés, consultando sobre las fortalezas y debilidades de los egresados contratados; encontró tres ejes de competencias a desarrollar en este programa: profesionales, formación humana y académicas, y concluye que varias demandas y necesidades de los profesores de francés no están incorporados en el perfil de egreso, las cuales corresponden a los nuevos cambios histórico-sociales del contexto actual. En esta misma línea, Maldonado y Vidal (2015) aplicaron una encuesta por correo a 31 egresados de Tecnología Médica sobre cuatro dominios de la competencia profesional. Los resultados indican un alto grado de satisfacción en el dominio asistencial (75\%) y en investigación (90\%); en educación, medianamente satisfactorio, y el más débil se ubicó en administración y gestión de laboratorios. Cevallos y 


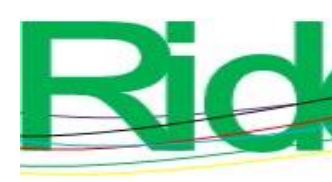

\section{Revista Iberoamericana para la Investigación y el Desarrollo Educativo ISSN 2007 - 7467}

Rosales (2019) aplicaron una encuesta a egresados luego de tres años de graduación. $94.3 \%$ de ellos se encuentra trabajando en su esfera de actuación, existe un alto nivel de empleabilidad y concluyen que hay buena coherencia entre las competencias adquiridas y las requeridas. Por último, Álvarez y De Prada (2018) hallaron resultados altos en las competencias evaluadas, excepto en cuanto a la creatividad, en donde obtuvieron los puntajes más bajos en el programa de Ciencias Empresariales y Turismo. Entonces, esta tendencia plantea el desafío de la evaluación externa del currículo, y particularmente del perfil de egreso a la luz de las demandas sociales, laborales y contar siempre con la opinión de los egresados y empleadores.

La evaluación del perfil de egreso en las carreras profesionales es una tarea y una responsabilidad institucional; debe ser abordada y realizada en sus diversas unidades, por los actores involucrados y en cada uno de los momentos o etapas de la formación, con mecanismos y normas que garanticen verificar los avances, logros y dificultades que muestran los estudiantes acerca de las competencias exigidas y comprometidas en el perfil de egreso. Este proceso debe ser entendido y aplicado como un sistema de aseguramiento de la calidad del logro de las competencias en la formación profesional desde el perfil de ingreso hasta el de egreso, con enfoque de mejora continua, conservando coherencia con las demandas sociales y laborales del contexto en cada grado y título profesional.

Las experiencias presentadas en las cinco tendencias (tablas 1, 2, 3 y 4) son concordantes a los planteamientos de la evaluación auténtica y de competencias (Ahumada, 2005; Brown, 2015; Díaz, 2005; Tobón 2013; Tobón et al., 2010; Villarroel y Bruna, 2019); permiten configurar y proponer la necesidad de organizar un sistema de evaluación del logro del perfil de egreso en sintonía con la evaluación de las competencias de las asignaturas, durante la formación y al final de los estudios, complementada con la opinión y sugerencias de los egresados y empleadores, para tomar decisiones de mejora continua. Para lograr este propósito, es vital la adecuada correspondencia entre el plan de estudios, las estrategias de enseñanza-aprendizaje y la evaluación de las asignaturas con las exigencias del perfil de egreso, lo cual debe estar garantizado desde el diseño curricular del grado universitario.

Sin embargo, en los estudios no se ahonda en las acciones de mejora implementadas, como la revisión de los currículos o mejora de las estrategias de formación y evaluación consecuencia del análisis de los resultados obtenidos, porque en la mayoría de los casos el 


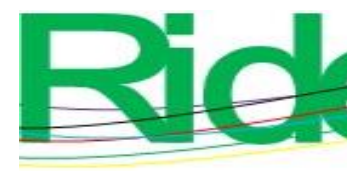

Revista Iberoamericana para la Investigación y el Desarrollo Educativo

ISSN $2007-7467$

nivel de logro del perfil de egreso, sobre todo al culminar los estudios universitarios, no es óptimo.

Hay una necesidad de profundizar y ampliar el estudio en los siguientes aspectos: $a$ ) realizar estudios empíricos acerca de la evaluación del logro del perfil de egreso en diversos grados universitarios por áreas de formación profesional y en diversos contextos internacionales; $b$ ) realizar estudios de validación de los instrumentos de evaluación del logro del perfil de egreso, con enfoques cuantitativos y cualitativos; $c$ ) sistematizar y evaluar las tendencias y aportes de estudios a nivel de tesis de pre y posgrado respecto a la evaluación del perfil de egreso y su logro, y $d$ ) realizar estudios acerca de las propuestas y avances sobre el sistema de gestión integral y progresiva de la evaluación de competencias y del perfil de egreso en los grados a nivel institucional.

\section{Conclusiones}

El metaanálisis documental de publicaciones referidos a la evaluación del logro del perfil de egreso nos ha permitido plantear algunas conclusiones.

Existen experiencias de evaluación del logro del perfil de egreso en diversos grados y universidades con una riqueza de aportes en cuanto la definición del perfiles de egreso, el uso de instrumentos de evaluación aplicados durante la formación y al final de los estudios universitarios, la participación de varios actores, como los estudiantes, egresados, docentes y los empleadores.

Las experiencias de la evaluación del logro del perfil de egreso en diversos grados universitarios pueden agruparse en cinco tendencias: $a$ ) coherencia entre plan de estudios e instrumentos de evaluación de asignaturas con el logro del perfil de egreso; $b$ ) al final de los estudios universitarios; $c$ ) progresiva durante la formación; $d$ ) progresiva y al final de los estudios universitarios, y e) evaluación por egresados y empleadores.

Existe la necesidad de implementar un sistema progresivo, integral y participativo de evaluación del logro del perfil de egreso en los grados universitarios, basado en el conocimiento, la experiencia y los desafíos planteados a la universidad.

Para garantizar una formación exitosa y competente de los egresados, los grados universitarios deben abordar y superar algunos desafíos, entre ellos: a) asegurar el alineamiento y coherencia interna entre perfil de egreso y el plan de estudios, $b$ ) asegurar y monitorear que las estrategias de enseñanza-aprendizaje, los criterios e instrumentos de 


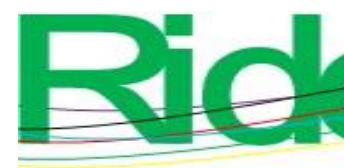

\section{Revista Iberoamericana para la Investigación y el Desarrollo Educativo ISSN 2007 - 7467}

evaluación de las asignaturas o equivalentes estén alineados a las exigencias de las competencias del perfil de egreso, $c$ ) asegurar la evaluación progresiva y participativa del avance y logro de las competencias del perfil de egreso durante la formación y $d$ ) organizar un sistema de evaluación del logro del perfil de egreso dentro del sistema de evaluación de la formación profesional a nivel institucional.

\section{Referencias}

Ahumada, P. (2005). La evaluación auténtica : un sistema para la obtención de evidencias y vivencias de los aprendizajes. Perspectiva Educacional, 45, 11-24.

Álvarez, M. y y De Prada, E. (2018). Evaluación de las competencias profesionales a través de las prácticas externas: incidencia de la creatividad. Revista de Investigación Educativa, 36(1), 203-219.

Ampuero, N., Báez, M., Castillo, C., Lagos, J., Loncomilla, L., Núñez, F., Pérez, C. y Poblete A. (2017) La evaluación progresiva del logro del perfil de egreso. En Centro Interuniversitario de Desarrollo [Cinda], Evaluación del logro de perfiles de egreso: experiencias universitarias. Santiago, Chile: Centro Interuniversitario de Desarrollo. Recuperado de https://cinda.cl/wp-content/uploads/2017/07/evaluacion-del-logrode-perfiles-de-egreso-experiencias-universitarias.pdf.

Arribas, J. M., Manrique, J. C. y Tabernero, J. (2016). Instrumentos de evaluación utilizados en la formación inicial del profesorado y su coherencia para el desarrollo de competencias profesionales en los estudiantes: visión del alumnado, egresados y profesorado. Revista Complutense de Educación, 27(1), 237-255.

Barrera, S. (2009). Evaluación del perfil de egreso en programas de pedagogía, una experiencia piloto en la Universidad Católica Silva Henríquez (UCSH). Foro Educacional, $\quad$ (16), 85-120. Recuperado de https://doi.org/10.29344/07180772.16.621.

Brown, S. (2015). La evaluación auténtica: el uso de la evaluación para ayudar a los estudiantes a aprender. Relieve, 21(2). Recuperado de http://dx.doi.org/10.7203/relieve.21.2.7674.

Cano, E. (2008). La evaluación por competencias en la educación superior. Revista de Currículum y Formación de Profesorado, 12(3), 1-16. 


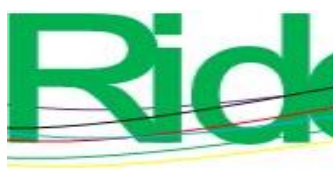

\section{Revista Iberoamericana para la Investigación y el Desarrollo Educativo ISSN 2007 - 7467}

Carrera, C., Lara, Y. I. y Madrigal, J. (2019) Evaluación del logro del perfil de egreso. Un estudio de caso. Revista Electrónica Científica de Investigación Educativa, 4(2), 1019-1028.

Castillo, S. y Cabrerizo, J. (2009). Evaluación educativa de aprendizajes y competencias. Madrid, España: Pearson Educación.

Champin, D. (2014). Evaluación por competencias en la educación médica. Revista Peruana de Medicina Experimental y Salud Pública, 31(3), 566-571.

Cevallos, C. J. y Rosales, F. R. (2019). Resultados del seguimiento a graduados. Evaluación cualitativa de la carrera de educación física, deportes y recreación, ULEAM, Manta, Ecuador. Olimpia. Revista de la Facultad de Cultura Física de la Universidad de Granma, 16(53), 117-190.

Ceballos, E., Ceballos, O., Cocca, A. y Alfonso, M. R. (2015). Perfil de egreso 2002/2011 de licenciatura en educación física. Revista Iberoamericana para la Investigación y el Desarrollo Educativo, 6(11).

Centro Interuniversitario de Desarrollo [Cinda]. (2017). Evaluación del logro de perfiles de egreso: experiencias universitarias. Santiago, Chile: Centro Interuniversitario de Desarrollo. Recuperado de https://cinda.cl/wp-content/uploads/2017/07/evaluaciondel-logro-de-perfiles-de-egreso-experiencias-universitarias.pdf.

Díaz, F. (2005). La evaluación auténtica centrada en el desempeño: una alternativa para evaluar el aprendizaje y la enseñanza. En Díaz, F., Enseñanza situada: vínculo entre la escuela y la vida (pp. 125-161). México: McGraw-Hill. Recuperado de https://liceo53.files.wordpress.com/2013/07/la_evaluacion_autentica_centrada_en_e 1_desempenodc3adazbarriga.pdf.

Díaz, F. y Barroso, R. (2014). Diseño y validación de una propuesta de evaluación auténtica de competencias en un programa de formación de docentes de educación básica en méxico. Perspectiva Educacional, 53(1), 36-56.

Fernández, A. (2010). La evaluación orientada al aprendizaje en un modelo de formación por competencias en la educación universitaria. Revista de Docencia Universitaria, 8(1), 11-34.

Flores, J. y Barajas, G. (2016). Evaluación de competencias profesionales mediante la experiencia adquirida por los estudiantes en sus estadías prácticas. Revista Educación en Ingeniería, 13(26), 27-34. 


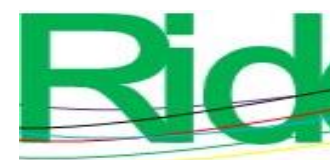

Revista Iberoamericana para la Investigación y el Desarrollo Educativo ISSN 2007 - 7467

González, K., Mortigo, A. y Berdugo, N. (2014). La configuración de perfiles profesionales en la educación superior y sus implicaciones en el currículo. Revista Científica General José María Córdova, 22(14), 165-182.

Izquierdo, C. y Loarte, W. (2014). Evaluación del desempeño del egresado de la carrera de Ingeniería Comercial de la Universidad Politécnica Salesiana - Ecuador. Revista Retos, 7(1), 45-61.

Jiménez, Y., Gutiérrez, J. y Hernández, J. (2019). Logros y desafíos en la formación de competencias transversales por áreas de conocimiento en la educación superior del Instituto Politécnico Nacional (México). Formación Universitaria, 12(3), 91-100.

Jiménez, J. A., Machado, J. P., Caso, J. y Arrayales, E. M. (2019). Evaluación del egreso de la licenciatura en actividad física y deportes de la UABC: Un ejercicio comprensivo. REICE. Revista Iberoamericana sobre Calidad, Eficacia y Cambio en Educación, 17(2), 123-146.

Jiménez, F., Martínez, G., Sánchez, G., Juárez, J. M. y Paredes, S. (2009). Un sistema de evaluación basado en competencias : Ejemplo para la asignatura Tecnología de la Programación del título de Grado en Ingeniería Informática por la Universidad de Murcia. Ponencia presentada en las XV Jornadas de enseñanza universitaria de la informática. Barcelona, del 8 al 10 de julio de 2009. Recuperado de https://upcommons.upc.edu/bitstream/handle/2099/7871/p98.pdf?sequence=6\&isAll owed $=\mathrm{y}$.

Leiva, M. V. e Iglesias, R. (2017). Sistema de aseguramiento de la calidad del proceso de logro de competencias profesionales en programas de formación de profesores. La experiencia de la Pontificia Universidad Católica de Valparaíso. En Centro Interuniversitario de Desarrollo [Cinda], Evaluación del logro de perfiles de egreso: experiencias universitarias. Recuperado de https://cinda.cl/wpcontent/uploads/2017/07/evaluacion-del-logro-de-perfiles-de-egreso-experienciasuniversitarias.pdf.

López, V. M. (2010). El papel de la evaluación formativa en la evaluación por competencias: aportaciones de la red de evaluación formativa y compartida en docencia universitaria. REDU: Revista de Docencia Universitaria, 9(1). Recuperado de http://redaberta.usc.es/redu/index.php/REDU.

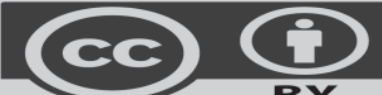




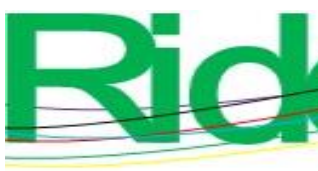

Revista lberoamericana para la Investigación y el Desarrollo Educativo ISSN 2007 - 7467

López, G., Molina, V., Rebolledo, X. y Suárez, M. (2017). Nivel de logro de las competencias profesionales y genéricas en la formación de enfermería. Revista Iberoamericana de Educación e Investigación en Enfermería, 7(4), 34-43.

Maldonado, M. y Vidal, S. (2015). Evaluación de competencias profesionales en egresados de tecnología médica. Revista Cubana de Educación Médica Superior, 29(3), 435447.

Mateo, J. (2005). La evaluación educativa, su práctica y otras metáforas. Barcelona, España: ICE-Horsori.

Möller, I. y Gómez, H. (2014). Coherencia entre perfiles de egreso e instrumentos de evaluación en carreras de educación básica en Chile. Calidad en la Educación, (41), $17-49$.

Morales, S. y Zambrano, H. (2016). Coherencia evaluativa en formación universitaria por competencias: estudio en futuros educadores en Chile. Infancias Imágenes, 15(1), 926.

Muñoz, C. A., Latrach, C., González, I. y Araya, M. (2010). Evaluación de competencia del nivel bachiller: "aseguramiento de la calidad en la formación de estudiantes de enfermería". Ciencia y Enfermería, 16(1), 77-84.

Muñoz, M. y Martínez, C. (2016). Seguimiento del logro del perfil de egreso en ingeniería civil informática de la UCSC. XXIX Congreso Chileno de Educación en Ingeniería UFRO 2016. Recuperado de http://sochedi2016.ufro.cl/wpcontent/uploads/2016/10/SOCHEDI_2016_paper_28.pdf

Murillo, B. y Trujillo, S. E. (2010). Percepción del desempeño por competencias de los estudiantes de internado de la Universidad Tecnológica de Pereira. Revista Médica de Risaralda, 16(2), 31-42.

Olivos, M., Voisin, S. y Fernández, J. (2015). Evaluación del perfil de egreso de profesores de francés de parte de los empleadores:propuestas de mejora y desarrollo. Actualidades Investigativas en Educación, 15(1). Recuperado de https://revistas.ucr.ac.cr/index.php/aie/article/view/17590.

Ortiz, A., Venegas, M. y Espinoza, M. (2015). Diseño de un sistema para la verificación del desarrollo de una competencia del perfil del egresado. FEM: Revista de la Fundación Educación Médica, 18(1), 71-77.

Pimienta, J. H. (2012). Las competencias en la docencia universitaria. México: Pearson. 


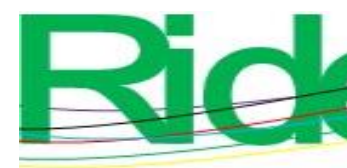

\section{Revista Iberoamericana para la Investigación y el Desarrollo Educativo ISSN 2007 - 7467}

Pucuhuaranga, T., Hilario, N. y Huamán, L. (2019). Modelo de evaluación del perfil de egreso en estudiantes de educación - Universidad Nacional del Centro del Perú. Revista $\quad$ Espacios, $27 . \quad 39), \quad$ Recuperado de https://www.revistaespacios.com/a19v40n39/19403927.html.

Sánchez, G. (2014). Evaluar competencias a partir de la autenticidad: implicaciones en la docencia universitaria. Revista Ensayos Pedagógicos, 9(1), 15-27.

Sepúlveda A., Opazo, M. y Díaz, D. (2018). Competencias sello en la universidad: promoción y evaluación en Pedagogía Básica. Cuadernos de Investigación Educativa, 9(1), 35-46. Recuperado de http://dx.doi.org/10.18861/cied.2018.9.1.2819.

Tejada, J. y Ruiz, C. (2016). Evaluación de competencias profesionales en educación superior: Retos e implicaciones. Educación XX1, 19(1), 17-38.

Tobón, S. (2013). Formación integral y competencias : pensamiento complejo, currículo, didáctica y evaluación.Colombia: ECO Ediciones.

Tobón, S. (2017). Evaluación socioformativa. Estrategias e instrumentos. Mount Dora (USA): Kresearch.

Tobón, S. Pimienta, J. H. y García, J.A. (2010). Secuencias didácticas: aprendizaje y evaluación. México: Pearson Educación.

Valverde, J., Revuelta, F. I. y Fernández, R. M. (2012). Modelos de evaluación por competencias a través de un sistema de gestión de aprendizaje. Revista Iberoamericana de Educación, 60(60), 51-62.

Villa, A. y Poblete, A. (2007). Aprendizaje basado en competencias.Una propuesta para la evaluación de las competencias genéricas. España: Universidad de Deusto-Ediciones Mensajero.

Villarroel, V. y Bruna, D. (2019). ¿Evaluamos lo que realmente importa?. El desafío de la evaluación auténtica en educación superior. Calidad en la Educación, (50), 492-509. Recuperado de https://www.calidadenlaeducacion.cl/index.php/rce/article/view/729 


\begin{tabular}{|c|c|}
\hline Rol de Contribución & Autor (es) \\
\hline Conceptualización & $\begin{array}{l}\text { Ludencino A. Huamán Huayta (principal)Teresa N. } \\
\text { Pucuhuaranga Espinoza (apoya) y Nora E. Hilario Flores } \\
\text { (apoya) }\end{array}$ \\
\hline Metodología & $\begin{array}{l}\text { Ludencino A. Huamán Huayta, Teresa N. Pucuhuaranga } \\
\text { Espinoza y Nora E. Hilario Flores (iguales) }\end{array}$ \\
\hline Software & No se requirió \\
\hline Validación & No se requirió \\
\hline Análisis Formal & Ludencino A. Huamán Huayta \\
\hline Investigación & $\begin{array}{l}\text { Ludencino A. Huamán Huayta, (principal)Teresa N. } \\
\text { Pucuhuaranga Espinoza (apoya) y Nora E. Hilario Flores } \\
\text { (igual) }\end{array}$ \\
\hline Recursos & $\begin{array}{l}\text { Ludencino A. Huamán Huayta,(igual) Teresa N. Pucuhuaranga } \\
\text { Espinoza (igual) y Nora E. Hilario Flores (igual) }\end{array}$ \\
\hline Curación de datos & $\begin{array}{l}\text { Ludencino A. Huamán Huayta, Teresa N. Pucuhuaranga } \\
\text { Espinoza y Nora E. Hilario Flores (iguales) }\end{array}$ \\
\hline $\begin{array}{l}\text { Escritura - Preparación del } \\
\text { borrador original }\end{array}$ & $\begin{array}{l}\text { Ludencino A. Huamán Huayta, Teresa N. Pucuhuaranga } \\
\text { Espinoza y Nora E. Hilario Flores (iguales) }\end{array}$ \\
\hline $\begin{array}{l}\text { Escritura - Revisión y } \\
\text { edición }\end{array}$ & $\begin{array}{l}\text { Ludencino A. Huamán Huayta (principal), Teresa N. } \\
\text { Pucuhuaranga Espinoza (apoya) y Nora E. Hilario Flores } \\
\text { (igual) }\end{array}$ \\
\hline Visualización & Ludencino A. Huaman Huayta \\
\hline Supervisión & Ludencino A. Huaman Huayta \\
\hline $\begin{array}{l}\text { Administración de } \\
\text { Proyectos }\end{array}$ & Ludencino A. Huaman Huayta \\
\hline Adquisición de fondos & $\begin{array}{l}\text { Ludencino A. Huamán Huayta, Teresa N. Pucuhuaranga } \\
\text { Espinoza y Nora E. Hilario Flores. (igual) Universidad } \\
\text { Nacional del Centro del Perú (principal) }\end{array}$ \\
\hline
\end{tabular}

